\title{
Neutrophilic Eccrine Hidradenitis in a Primary CNS Lymphoma Patient Receiving High-Dose Chemotherapy
}

Jasmine Saleh $^{1}$, Brooke Vasicek ${ }^{2}$, Jeave Reserva ${ }^{2}$, Eden Lake ${ }^{2}$ and Jodi Speiser ${ }^{*}$

${ }^{1}$ Department of Pathology, Loyola University Medical Center, Maywood, Illinois

${ }^{2}$ Department of Dermatology, Loyola University Medical Center, Maywood, Illinois

*Corresponding author: Jodi Speiser, MD, Department of Pathology, 2160 S $1^{\text {st }}$ Ave, Maywood, IL, 60153, Tel: 708-327-2614; E-mail: jspeiser@lumc.edu

Received date: December 19, 2018; Accepted date: January 16, 2019; Published date: January 24, 2019

Copyright: @2019 Saleh J, et al. This is an open-access article distributed under the terms of the Creative Commons Attribution License, which permits unrestricted use, distribution, and reproduction in any medium, provided the original author and source are credited.

Abstract
Neutrophilic Eccrine Hidradenitis (NEH) is a rare inflammatory neutrophilic dermatosis that primarily affects
eccrine sweat glands. Although it has been described in various malignancies and with therapeutic agents, it is most
frequently associated with cytarabine-based induction chemotherapy for acute myelogenous leukemia. We report a
rare case of NEH in a 63-year-old male with a medical history significant for primary CNS lymphoma. The patient
was treated with high-dose thiotepa, busulfan, and cyclophosphamide (BuCy) followed by autologous stem cell
transplantation, which was complicated by bacteremia and septic shock. Approximately three weeks after
chemotherapy, he developed localized bright red, desquamating plaques on his bilateral outer hips, posterior upper
thighs, and buttocks. Histological findings revealed neutrophils infiltrating and surrounding the eccrine glands
accompanied by squamous syringometaplasia, apoptotic keratinocytes, and basovacuolar changes. This case
serves to highlight that NEH should be considered in the differential diagnosis of erosive, erythematous plaques,
especially in patients with lymphoproliferative tumors receiving high-dose chemotherapy, in order to provide
appropriate clinical management.

Keywords: Neutrophilic eccrine hidradenitis; Primary CNS lymphoma; Chemotherapy; Eccrine glands; Neutrophils

\section{Introduction}

Chemotherapy with thiotepa, busulfan, and cyclophosphamide (BuCy) followed by autologous stem cell transplantation has been adopted as the treatment of the primary Central Nervous System (CNS) lymphoma [1]. High-dose chemotherapy has been associated with Neutrophilic Eccrine Hidradenitis (NEH) in patients with acute myelogenous leukemia [2]. NEH is described as a neutrophilic dermatosis characterized by neutrophilic infiltrates predominantly in the dermis without any identifiable source of infection [3]. To our knowledge, we present the first case of Neutrophilic Eccrine Hidradenitis (NEH) in an adult patient receiving high-dose chemotherapy for primary CNS lymphoma.

\section{Case Report}

A 63-year-old male with a history of primary CNS lymphoma presented with fever and erythematous plaques on the buttocks and lower extremities. Three weeks prior to presentation, the patient was treated with high-dose chemotherapy (thiotepa and BuCy) followed by autologous stem cell transplantation, which was complicated by Klebsiella and Pseudomonas bacteremia and septic shock. On physical examination, a few well-circumscribed erythematous erosions with overlying white crust were noted on the outer thighs (Figure 1). On the buttocks and upper posterior thighs were bright red, eroded plaques with overlying fine white desquamation. A punch biopsy was performed on his right anterior thigh out of concern for acute graft versus host reaction versus a drug reaction.

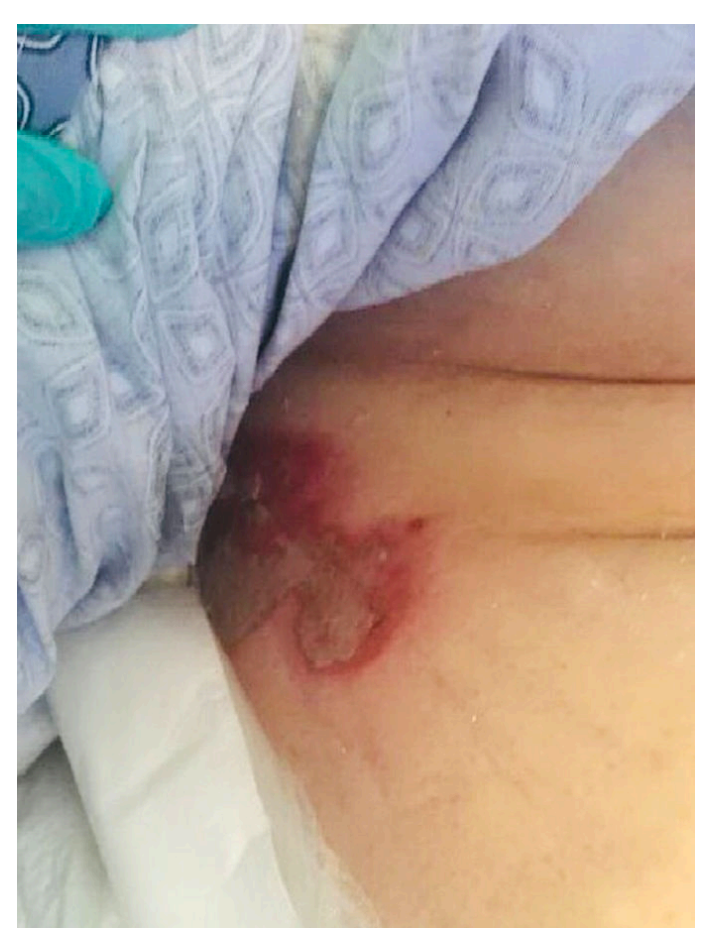

Figure 1: Clinical appearance of desquamating plaques on the hip. 


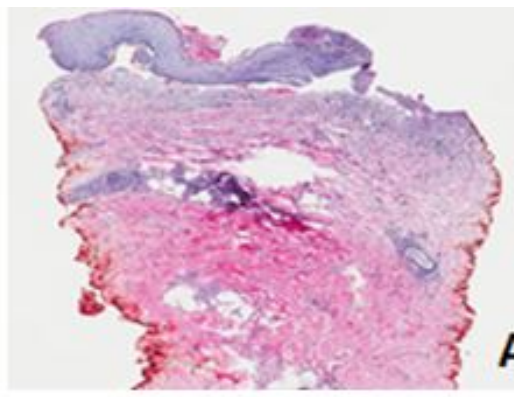

A
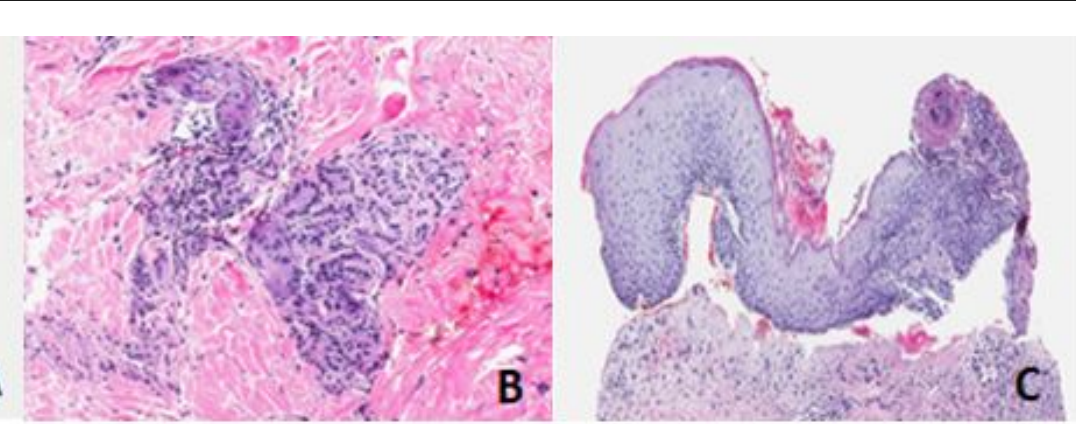

Figure 2: Neutrophilic eccrine hidradenitis. Histological examination demonstrates interface dermatitis with underlying superficial and deeply mixed inflammatory infiltrates with predominantly neutrophils (A). Prominent peri-eccrine inflammation with neutrophils accompanied by squamous syringometaplasia in the superficial and mid dermis (B) and apoptotic keratinocytes with basovacuolar changes (C) are shown.

Histological examination revealed prominent peri-eccrine inflammation with neutrophils and squamous syringometaplasia in the superficial and mid-dermis (Figure 2). Interface dermatitis with apoptotic keratinocytes and bilateral basovacuolar change with an underlying superficial and deep mixed inflammatory infiltrate of predominantly neutrophils were also observed. There was no evidence of vasculitis or hemorrhage. The fungal and bacterial cultures were negative. These findings were most consistent with NEH secondary to high-dose thiotepa and BuCy. While the patient's history of recent autologous stem cell transplantation was concerning for acute graft versus host reaction, the changes in eccrine glands seen in NEH are not observed in this diagnosis. The patient was treated with triamcinolone $0.1 \%$ ointment and silver sulfadiazine cream twice daily.

\section{Discussion}

$\mathrm{NEH}$ is a rare neutrophilic dermatosis primarily affecting the eccrine glands [2]. Although most cases are reported in association with cytarabine-based induction chemotherapy for acute myelogenous leukemia [2], NEH is rarely observed in lymphoproliferative disorders [2]. It has been previously reported in one case of Hodgkin's lymphoma and one pediatric case of a non-Hodgkin's lymphoma [4,5]. Demographics and clinical characteristics of these cases are summarized in Table 1 [4-15]. NEH has also been described in adult patients with other malignancies and solid tumors, including chronic lymphocytic leukemia, osteogenic sarcoma, testicular carcinoma, metastatic breast cancer, Bechet disease, HIV and Wilms tumor $[2,4,5]$. Granulocyte colony-stimulating factor, acetaminophen, anti-retroviral agents, and other chemotherapeutic agents (i.e. anthracyclines, mitoxantrone, cyclophosphamide, bleomycin, imatibib, methotrexate, and topotecan) have been reported to induce NEH as well $[2,4,5]$. Belot et al. reported one case without an associated disease or therapeutic agent [16].

NEH clinically manifests 2 days to 3 weeks following the induction of chemotherapy [2]. As demonstrated in Table 1, it presents as erythematous plaques typically located on the face, trunk, palms, or extremities, with or without associated fever or neutropenia $[2,5,6]$. Differential diagnosis may include erythema multiforme, leukemia cutis, drug hypersensitivity, vasculitis, bullous pyoderma, Sweet's syndrome and pyoderma gangrenosum [17].

\begin{tabular}{|c|c|c|c|c|c|}
\hline Case & Gender & Age & $\begin{array}{l}\text { Underlying } \\
\text { leukemia/ } \\
\text { lymphoproliferative disorder }\end{array}$ & Clinical presentation & References \\
\hline Bailey et al & M & 11 & Non-Hodgkin's lymphoma & Widespread erythematous papulopustules & 4 \\
\hline Beutner et al & M & 44 & Hodgkin's lymphoma & $\begin{array}{l}\text { Erythematous macules and plaques with } \\
\text { associated fever }\end{array}$ & 5 \\
\hline Srivastava et al & $\mathrm{F}$ & 73 & Acute myelogenous leukemia & Erythematous plaques mimicking facial cellulitis & 6 \\
\hline Katsanis et al & $\mathrm{F}$ & 11 & Acute myelogenous leukemia & Erythematous eruption & 7 \\
\hline Salik et al & $\mathrm{F}$ & 4 & Acute myelogenous leukemia & $\begin{array}{l}\text { Tender erythematous and painful papules } \\
\text { involving the trunk, extremities and face }\end{array}$ & 8 \\
\hline Taghy et al & M & 47 & Acute myelogenous leukemia & $\begin{array}{l}\text { Itchy, erythematous-papular palmer lesion with } \\
\text { fever }\end{array}$ & 9 \\
\hline Grahovac et al & $\mathrm{F}$ & 51 & Acute myelogenous leukemia & $\begin{array}{l}\text { Periorbital cellulitis-like lesions and blanching } \\
\text { urticarial papules and plaques on the trunk }\end{array}$ & 10 \\
\hline
\end{tabular}




\begin{tabular}{|l|l|l|l|l|}
\hline Copaescu et al & M & 58 & Acute myelogenous leukemia & $\begin{array}{l}\text { Dark erythematous, violaceous and edematous } \\
\text { plaques on the right and left periorbital areas, } \\
\text { on the nose root, and on the neck }\end{array}$ \\
\hline Sanober et al & M & 62 & Acute myelogenous leukemia & $\begin{array}{l}\text { Bilateral periocular erythematous } \\
\text { edematous maculopapular lesions }\end{array}$ \\
\hline Ng et al & F & 30 & Acute myelogenous leukemia & $\begin{array}{l}\text { Fever, chills, and painful cutaneous eruption } \\
\text { over the right shin and left elbow }\end{array}$ \\
\hline Bardenstein et al & M & 30 & Acute myelogenous leukemia & Periobital swelling, fever, and neutropenia. \\
\hline Brehler et al & F & 43 & Acute myelogenous leukemia & Tender nodules in bilateral axillae \\
\hline
\end{tabular}

Table 1: Demographic and clinical characteristics of cases with associated leukemia and lymphoproliferative diseases.

The diagnosis of NEH is based on histological findings [18]. It is characterized by dense neutrophilic infiltrating and surrounding the eccrine glands, which may be accompanied by dermal edema and/or hemorrhage, squamous syringometaplasia, and necrosis of the eccrine coils and glands [2]. Epidermal spongiosis, basal vacuolization, and focal necrotic keratinocytes may also be present [9]. These findings in our case confirmed the diagnosis. Histopathological differential diagnosis includes, but is not limited to, acute urticaria, graft versus host disease, erythema nodosum, erythema multiforme, cellulitis, sweet syndrome, and erysipelas [3].

The pathogenesis of NEH has not been well-characterized. Harris et al., postulated that NEH may arise secondary to a direct cytotoxic effect of a therapeutic agent secreted in the sweat on the eccrine glands [19]. The damage of the glands may stimulate an inflammatory response and neutrophilic chemotaxis, which would lead to cellular damage and necrosis of the epithelial cells [2]. This may account for a majority of NEH cases, including our case, in patients receiving highdose chemotherapy. In contrast, other investigators proposed that $\mathrm{NEH}$ is part of the spectrum of neutrophilic dermatoses [18].

$\mathrm{NEH}$ is generally a benign, self-limiting condition [6]. Current treatment includes non-steroidal anti-inflammatory drugs and topical corticosteroids, which should be used with caution in patients with neutropenia [2]. Shear et al., demonstrated that administration of dapsone 48 hours prior to chemotherapy prevented recurrent $\mathrm{NEH}$ in a patient [20]. It is also important to exclude infection as well as another differential diagnosis by fungal and bacteria cultures to avoid unnecessary use of antibiotic or changes in chemotherapy regimens $[11,17]$.

\section{Conclusion}

NEH is a neutrophilic dermatosis characterized by neutrophilic infiltrates within and around eccrine glands. It should be considered in the differential diagnosis of eroded, erythematous plaques, especially in patients receiving high-dose chemotherapy for primary CNS lymphoma. A diagnosis of NEH should be based on histological findings to avoid unnecessary use of antibiotics and changes in chemotherapy regimens.

\section{References}

1. DeFilipp Z, Li S, El-Jawahri A, Armand P, Nayak L, et al. (2017) Highdose chemotherapy with thiotepa, busulan, and cyclophosphamide an autologous stem cell transplantation for patients with primary central nervous system lymphoma in first complete remission. Cancer 123: 3073-3079.

2. Ghuge PS, Karia PS, Malkani RH (2017) Neutrophilic eccrine hidradenitis in a patient of acute myeloid chemotherapy with cytarabine. Clin Cancer Investig J 6: 261-263.

3. Wu B, Krishnamurthy K (2018) Neutrophilic eccrine Hidradenitis. StatPearls. In Treasure Island (FL): StatPearls Publishing.

4. Bailey DL, Barron D, Lucky AW (1989) Neutrophilic eccrine hidradenitis: a case report and review of the literature. Pediatr Dermatol 6: 33-38.

5. Beutner KR, Packman CH, Markowitch W (1986) Neutrophilic eccrine hidradenitis associated with Hodgkin's disease and chemotherapy. A case report. Arch Dermatol 122: 809-811.

6. Srivastava M, Scharf S, Meehan SA, Polsky (2007) Neutrophilic eccrine hidradenitis masquerading as facial cellulitis. J Am Acad Dermatol 56: 693-696.

7. Katsanis E, Luke KH, Hsu E, Carpenter BF, Mantynen PR (1987) Neutrophilic eccrine hidradenitis in acute myelomonocytic leukemia. Am J Pediatr Hematol Oncol 9: 204-208.

8. Salik D, Kolivras A, Sass U, Huybrechts S, Dangoisse C (2014) Palmoplantar neutrophilic eccrine hidradenitis with general extension in a child in remission after acute lymphoblastic leukemia. Ann Dermatol Venereol 141: 285-289.

9. Taghy A, Hassam B (2014) Neutrophilic eccrine hidradenitis during acute myeloid leukemia. Pan Afr Med J 18: 72.

10. Grahovac M, Maximiliane Ehmann L, Flaig M, Reibke R, Wollenberg A (2012) Neutrophilic eccrine hidradenitis induced by cytarabine. Acta Dermatovenerol Croat 20: 272-275.

11. Copaescu AM, Castilloux F, Chababi-Atallah M, Sinave C, Bertrand J (2013) A classic clinical case: neutrophilic eccrine hidradenitis. Case Rep Dermatol 5: 340-346.

12. Sanober N, Talal S, Frisbie S, Ulahannan S, Boddupalli SS, et al. (2018) A rare presentation of neutrophilic eccrine hidradenitis in the management of acute myeloid leukaemia: a case report. J Cancer Sci Ther 10: 8.

13. Ng ES, Aw DC, Tan KB, Poon ML, Yap ES, et al. (2010) Neutrophilic eccrine hidradenitis associated with decitabine. Leuk Res 34: 130-132.

14. Bardenstein DS, Haluschak, Gerson S, Zaim MT (1994) Neutrophilic eccrine hidradenitis simulating orbital cellulitis. Arch Ophthalmol 112: 1460-1463.

15. Brehler R, Reimann S, Bonsmann G, Metze D (1997) Neutrophilic hidradenitis induced by chemotherapy involves eccrine and apocrine glands. Am J Dermatopathol 19: 73-78.

16. Belot V, Perrinaud A, Corven C, de Muret A, Lorette G, et al. (2006) Adult idiopathic neutrophilic eccrine hidradenitis treated with colchicine. Presse Med 35: 1475-1478.

17. Wong GC, Lee LH, Chong YY (1998) A case report of neutrophilic eccrine hidradenitis in a patient receiving chemotherapy for acute myeloid leukaemia. Ann Acad Med Singapore 27: 860-863.

18. Bachmeyer C, Aractingi S (2000) Neutrophilic eccrine hidradenitis. Clin Dermatol 18: 319-330. 
Citation: Saleh J, Vasicek B, Reserva J, Lake E, Speiser J (2019) Neutrophilic Eccrine Hidradenitis in a Primary CNS Lymphoma Patient Receiving High-Dose Chemotherapy. Dermatol Case Rep 4: 147.

Page 4 of 4

19. Harrist TJ, Fine JD, Berman RS, Murphy GF, Mihm MC (1982) Neutrophilic eccrine hidradenitis. A distinctive type of neutrophilic dermatosis associated with myelogenous leukemia and chemotherapy. Arch Dermatol 118: 263-266.
20. Shear NH, Knowles SR, Shapiro L, Poldre P (1996) Dapsone in the prevention of recurrent neutrophilic eccrine hidradenitits. J Am Acad Dermatol 35: 819-822. 